\title{
SISTEMA DE BARRA SEGURA PARA DISTRIBUIÇÃO DE ENERGIA NA COMPANHIA SIDERÚRGICA DO PECÉM*
}

\author{
Fernando Zamboti Fortes ${ }^{1}$ \\ Paulo Ricardo Bastos de Queiroz 2 \\ Dirceu Gabriel Lindebeck ${ }^{3}$ \\ Carlos Ivan da Silva 4 \\ Hamilton Geraldo Martins ${ }^{5}$ \\ Alexandre Sandoval de Vasconcellos ${ }^{6}$
}

\section{Resumo}

Após estudo realizado, verificou-se que a CSP - Companhia Siderúrgica do Pecém, possuía alta vulnerabilidade às oscilações de frequência, sejam elas oriundas de falhas nas unidades geradoras ou problemas nas linhas de transmissão que compõem o SIN (Sistema Interligado Nacional), onde tais perturbações poderiam provocar desde a parada total da planta a danos irreversíveis em equipamentos como motores síncronos. Com base nesse estudo, foi implantado um sistema automatizado e de rápida resposta capaz de diminuir ou eliminar todos os efeitos provocados por tais distúrbios, atuando de forma dinâmica e coordenada com o cenário energético ao qual a planta siderúrgica encontra-se no momento do evento. Dentre os ganhos apontados em estudo, destaca-se a confiabilidade de se ter um sistema de distribuição de energia em uma usina siderúrgica capaz de assegurar a continuidade do processo ou em piores casos proporcionar uma parada emergencial com total segurança.

Palavras-chave: Distúrbio de frequência; Sistema de Proteção; Barra Segura; Confiabilidade Energética.

\section{SAFE BAR SYSTEM FOR ENERGY DISTRIBUTION AT COMPANHIA SIDERÚRGICA DO PECEM}

\section{Abstract}

After a study carried out, it was verified that CSP - Companhia Siderúrgica do Pecém, had high vulnerability to frequency oscillations, due to failures in the generating units or problems in the transmission lines that make up the SIN (National Interconnected System), where such disturbances could cause irreversible damage to equipment such as synchronous motors since the plant's total shutdown. Based on this study, an automated and fast response system was implemented, capable of reducing or eliminating all the effects caused by such disturbances, acting in a dynamic and coordinated way with the energy scenario which the steel plant is at the moment of the event. Among the gains pointed out in the study, the reliability of having an energy distribution system in a steel mill, capable of ensuring the continuity of the process or, in worse cases, providing an emergency stop with total security stands out.

Keywords: Frequency disturbance; Protection System; Safe Bar; Energy Reliability.

1 Superior Completo, Engenheiro Eletricista, Coordenador de Distribuição de Energia, Recebimento e Distribuição de Energia, CSP - Companhia Siderúrgica do Pecém.

2 Superior Incompleto, Técnico em Eletrotécnica, Técnico de Produção, Recebimento e Distribuição de Energia, CSP - Companhia Siderúrgica do Pecém.

3 Superior Completo, Engenheiro de Controle e Automação, Analista de Produção, Recebimento e Distribuição de Energia, CSP - Companhia Siderúrgica do Pecém.

4 Superior Incompleto, Técnico em Instrumentação, Técnico de Manutenção Elétrica, Manutenção de Energia e Utilidade, CSP - Companhia Siderúrgica do Pecém.

5 Superior Completo, Engenheiro Eletricista, Especialista em Manutenção, Manutenção de Energia e Utilidade, CSP - Companhia Siderúrgica do Pecém.

6 Superior Completo, Engenheiro Eletricista, Diretor, Área de Sistemas Elétricos de Potência, FIGENER. 


\section{INTRODUÇÃO}

Meios de contingências eficazes para a continuidade no fornecimento de energia elétrica em um cenário siderúrgico proporcionam maior confiabilidade de processo e estabilização do custo do mesmo. Dessa forma e sabendo-se do histórico de oscilações de frequência na região à qual a CSP está conectada, iniciou-se o estudo de estabilidade da planta em meio ao cenário energético.

Com carga instalada de aproximadamente 170MW e possuindo capacidade de geração interna de até $218 \mathrm{MW}$, a CSP está conectada no SIN através da subestação PECEM II, no subsistema Nordeste (figura 1) estando, portanto, suscetível aos balanços de cargas do Sistema Interligado Nacional. Por gerar energia através dos gases oriundos do processo de produção de aço e tendo suas cargas com consumo parcialmente instáveis, o fluxo de potência da usina é bastante dinâmico, onde em momentos a CSP é exportadora de energia e em outros caracteriza-se como consumidora, exigindo que o sistema implantado seja capaz de atuar conforme cenário atual de produção e geração de energia.

$O$ presente trabalho possui o objetivo de apresentar de forma sucinta, toda a metodologia aplicada para definição da filosofia de barra segura, bem como resultados alcançados e forma de implantação do novo sistema.

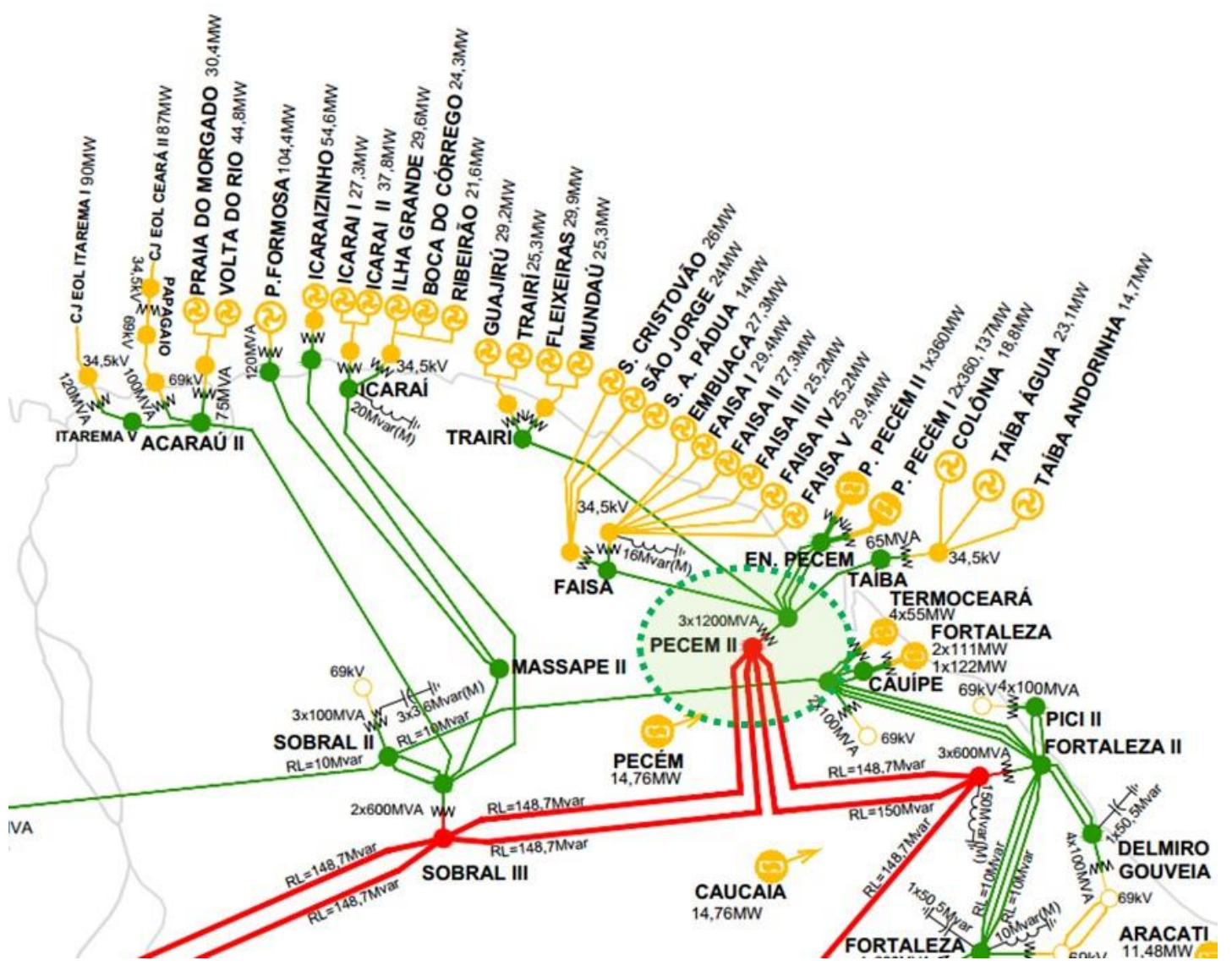

Figura 1. Representação do ponto de conexão da CSP ao SIN. 


\subsection{O SISTEMA ELÉTRICO DA CSP}

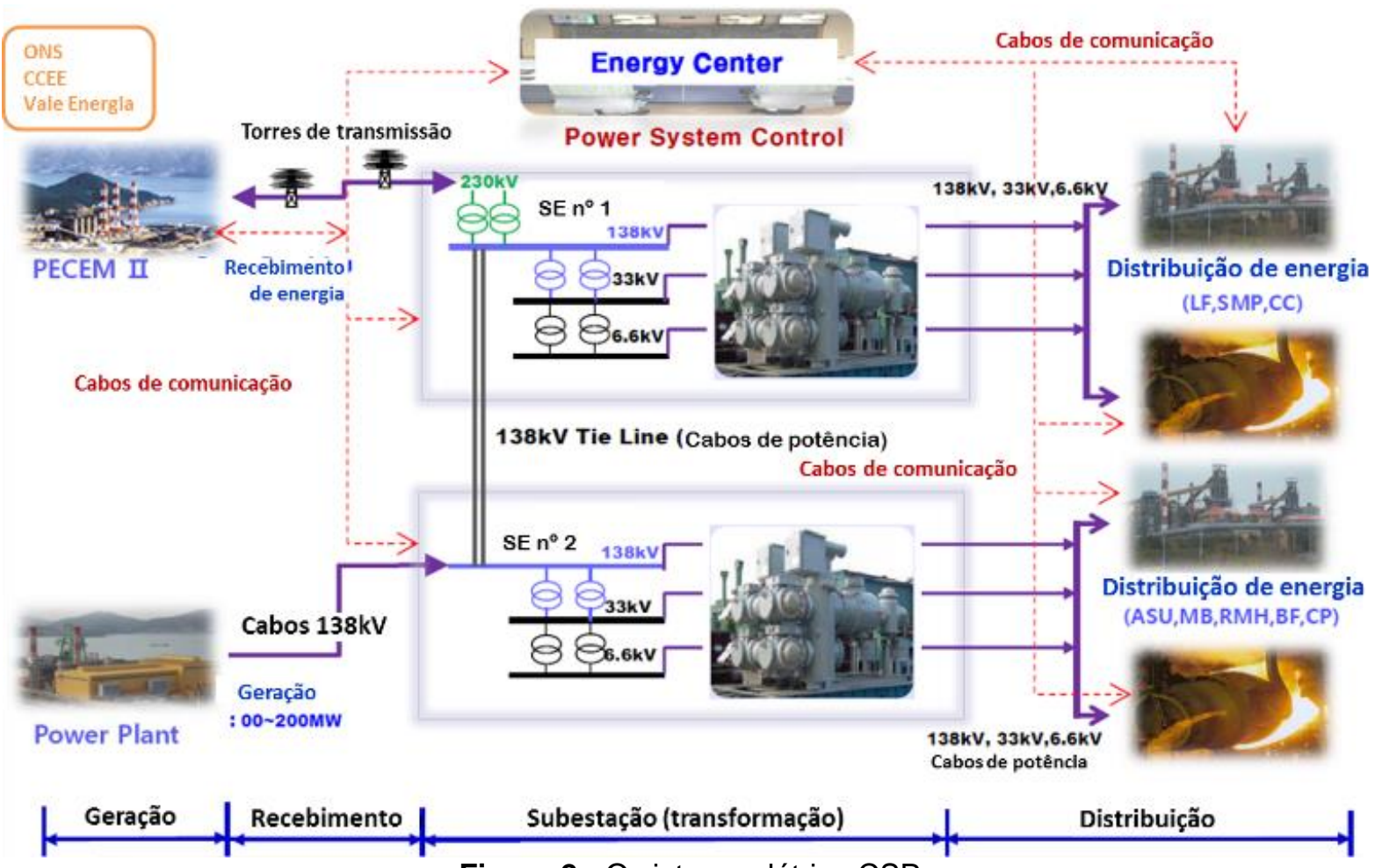

Figura 2: O sistema elétrico CSP.

A CSP possui duas subestações principais de alta tensão: A subestação 1 (SE-01), conectada à subestação externa de Pecem II por duas linhas de $230 \mathrm{kV}$. Ambas subestações (SE-01 e SE-02) possuem barramentos 138kV, 33kV e $6.6 \mathrm{kV}$ com seus respectivos consumidores e estão conectadas entre elas através de dois barramentos de 138kV (Tie lines). Na SE-02 também está conectada a termoelétrica (Power Plant), com duas unidades de geração com capacidade de $100 \mathrm{MW}$ cada.

Cada subestação possui dois barramentos para cada nível de tensão, sendo que nos níveis de $138 \mathrm{kV}$ e $33 \mathrm{kV}$ as cargas podem ser remanejadas para qualquer uma das duas barras, conforme exemplo na figura 3 abaixo.

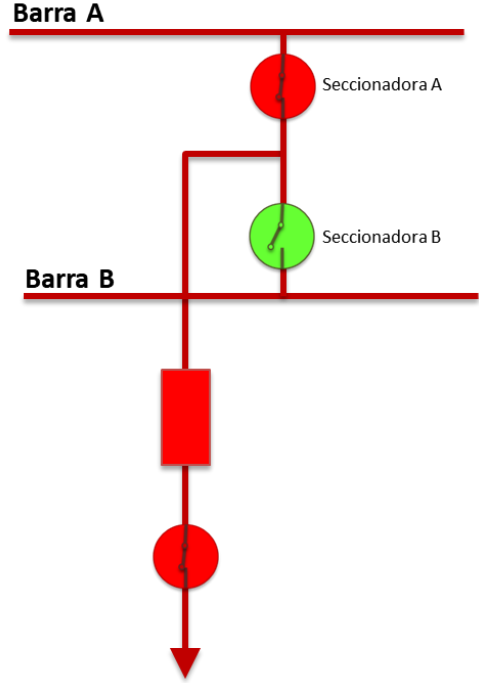

a) Carga conectada à barra $\mathrm{A}$

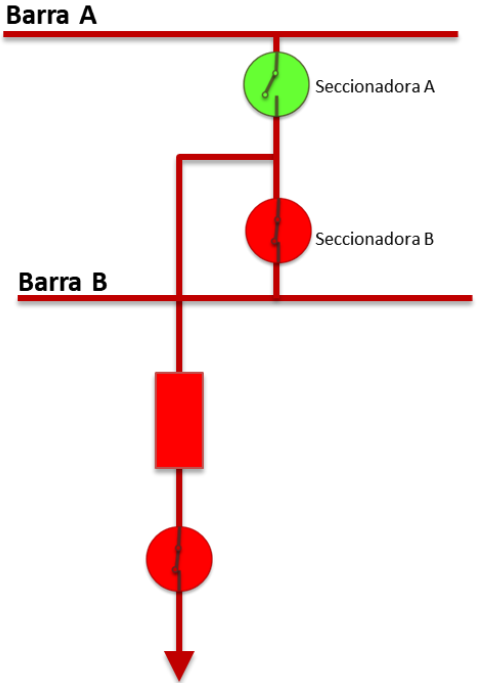

b) Carga conectada à barra $\mathrm{B}$

Figura 3: exemplo de disposição das cargas nas barras de 138kV e 33kV. 


\subsection{VISÃO DO SISTEMA}

O sistema de proteção implantado consiste em uma ferramenta automatizada e de rápida resposta, capaz de atuar de forma dinâmica e inteligente no sistema de distribuição de energia da CSP, em suas duas principais subestações (SE-01 e SE02), conforme figura 4:

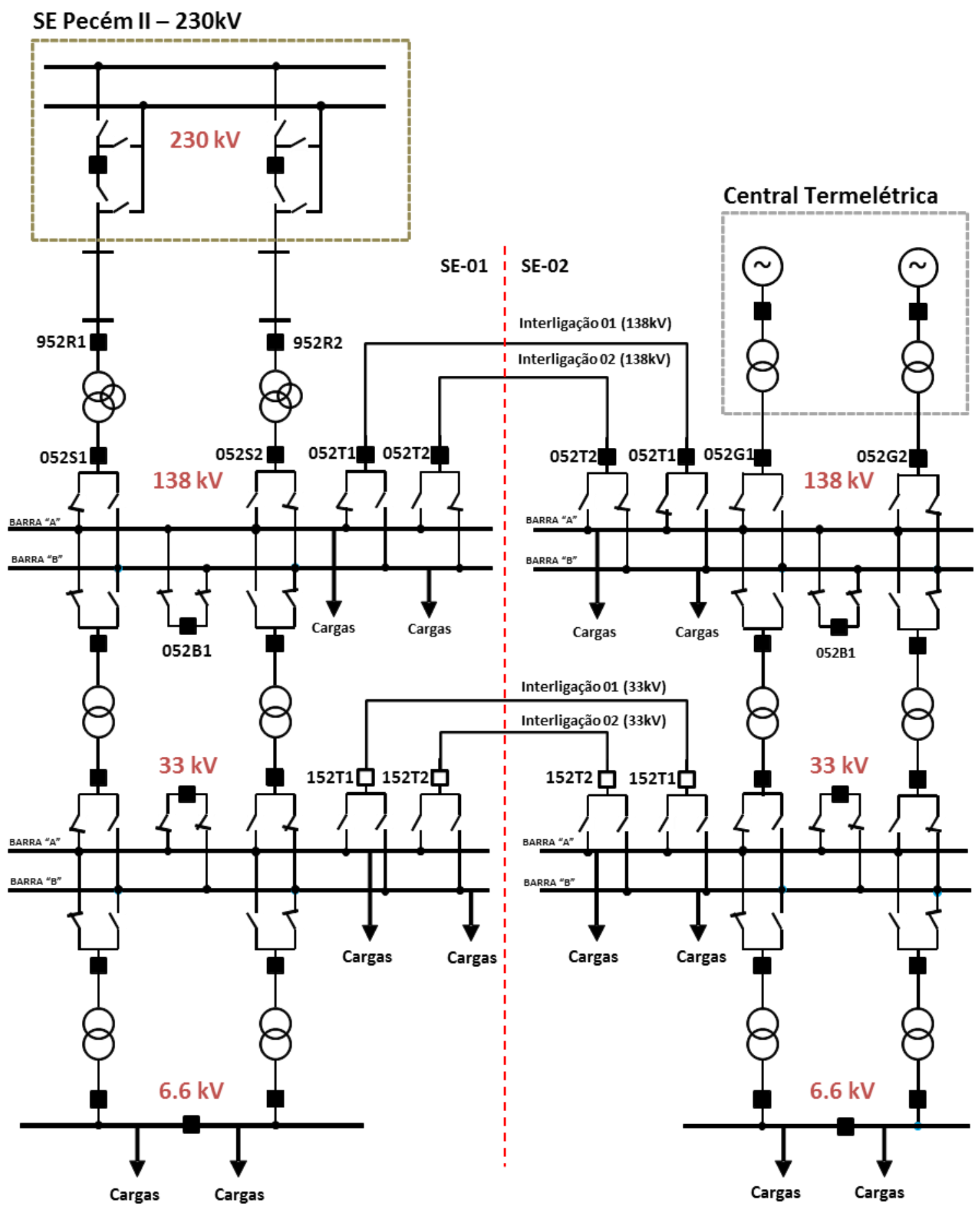

Figura 4. Diagrama das subestações antes da aplicação do sistema de barra segura. 
A configuração do sistema adotada antes da aplicação do projeto em questão possuía o objetivo único de proporcionar fontes de energia redundantes às cargas nele conectadas, dessa forma seria possível manter o fornecimento de energia elétrica das cargas em ambos os barramentos, porém em casos de distúrbio do SIN ou em seus equipamentos periféricos, todo o sistema de distribuição de energia da CSP seria sensibilizado, provocando atuações pontuais e não coordenadas das proteções de equipamentos fundamentais para continuidade do processo siderúrgico.

Com a instalação do projeto de barra segura, fez-se necessário efetuar modificações no sistema de proteção e controle, bem como nas configurações e mudanças no "modo operando" das subestações. Para que a atuação do sistema em questão fosse eficiente, os barramentos de $138 \mathrm{kV}, 33 \mathrm{kV}$ e $6.6 \mathrm{kV}$ foram distinguidos em prioritários e não prioritários e sua definição origina-se do ponto de conexão dos mesmos às suas respectivas fontes principais de fornecimento (sistema elétrico externo ou a termoelétrica), conforme figura 5 , onde a cor preta indica toda a divisão nomeada em não prioritário ou "NP" e a cor azul indica a divisão nomeada prioritária ou "P", estendendo-se tais definições às cargas conectadas.

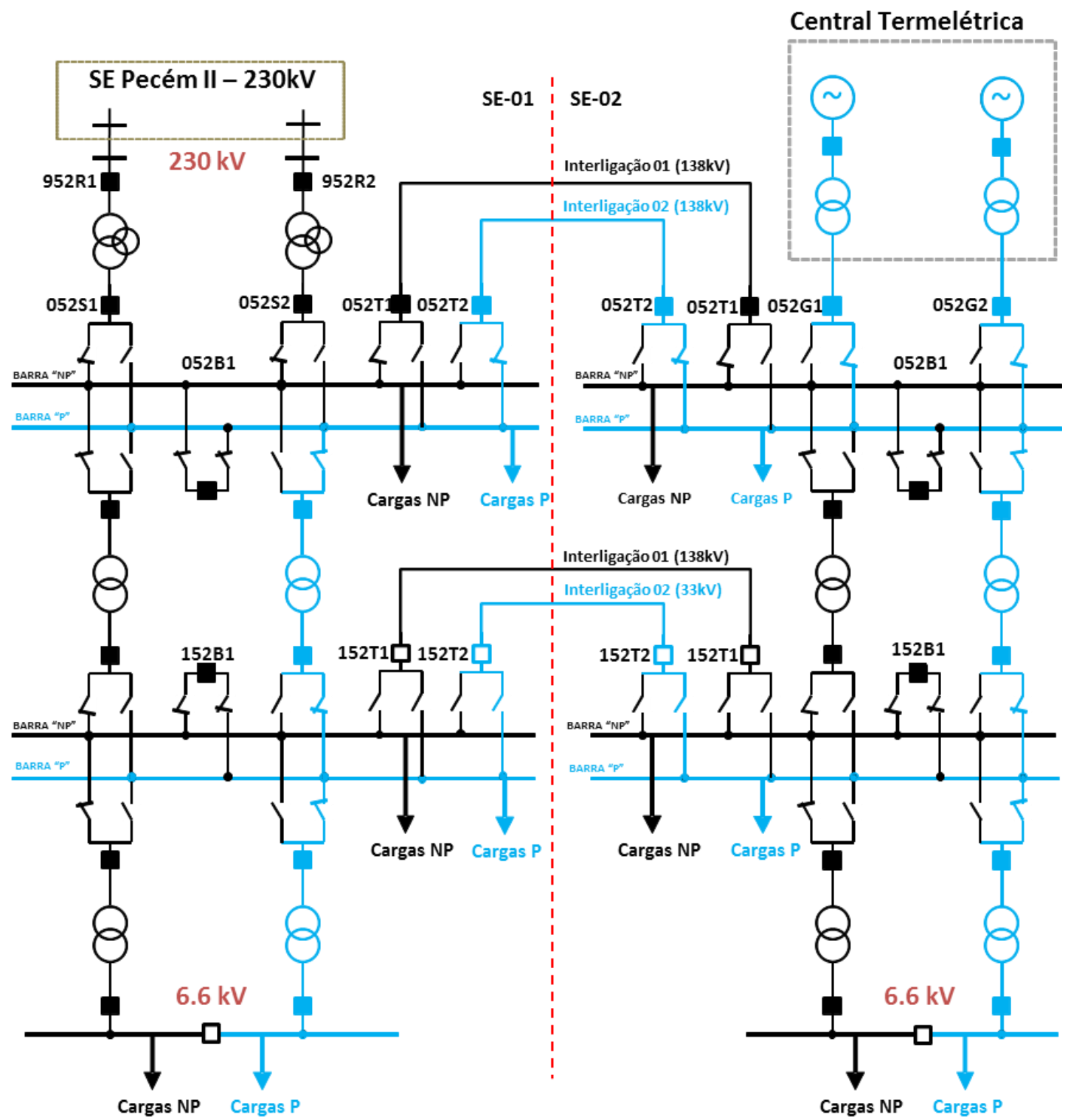

Figura 5. Diagrama subestações após aplicação do sistema de barra segura. 
Os barramentos conectados às unidades geradoras internas da planta, foram definidos como barramentos prioritários, já os barramentos conectados diretamente ou indiretamente ao SIN, foram definidos como barramentos não prioritários. Tal definição originou-se da afirmação de que a geração interna da planta possui sua estabilidade definida somente pelo processo siderúrgico e que déficits de geração podem ser previstos com base no cenário de produção da planta.

\subsection{OPERAÇÃO DO SISTEMA}

Toda a supervisão, processamento e geração de sinais para abertura de disjuntores ocorre na subestação SE-01, que faz fronteira com o SIN e onde estão localizados os relés de proteção responsáveis por supervisionar os níveis de frequência dos barramentos de $138 \mathrm{kV}$, bem como identificar o sentido da potência da planta em relação ao meio externo, através das funções de proteção $81 \mathrm{U} / \mathrm{O}$ e 32 (sub/sobre frequência e direcional de potência ativa, respectivamente). A figura 6 apresenta a lógica de funcionamento do sistema de barra segura, a qual resulta em duas formas de atuação, conforme cenário energético da planta no momento do distúrbio de frequência, conforme abaixo:

Caso PG>PC (Potência gerada > Potência consumo) - caso em que a CSP está em caráter de exportação de energia, podendo ser considerada autossuficiente e permitindo a desconexão total da planta do sistema externo em casos de distúrbios de frequência, gerando o mínimo de impacto possível nas cargas internas.

Caso PG<PC (Potência gerada < Potência consumo) - nesse caso a CSP está em caráter de consumidor, não permitindo a desconexão total do sistema externo. Com o objetivo de diminuir os impactos sobre as cargas prioritárias, o sistema faz a separação dos barramentos prioritários dos não prioritários através da abertura dos disjuntores de interligação das barras $138 \mathrm{KV}$ e 33KV das subestações SE-01 e SE02. Após separação, todas as cargas definidas como prioritárias terão seu fornecimento de energia oriundo da geração interna, já cargas definidas como não prioritárias estarão conectadas no sistema externo. Para assegurar a compatibilização da geração x carga, a geração interna deve ser continuamente monitorada com relação à carga total da usina, para que as cargas sejam remanejadas da barra prioritária para a não prioritária ou vice-versa, de acordo com a tabela de prioridade definida.

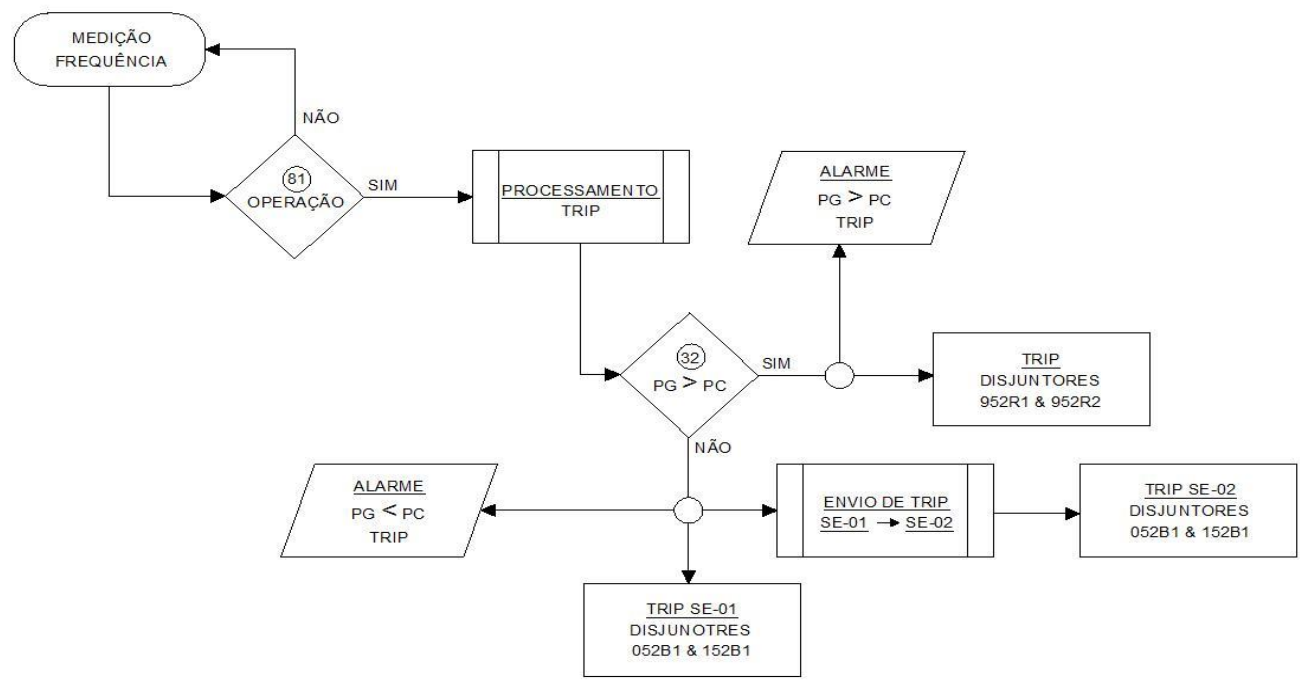

Figura 6. Fluxograma sistema de barra segura. 
A figura 7 apresenta a forma de operação do sistema de barra segura nas subestações envolvidas em ambos os casos de atuação.

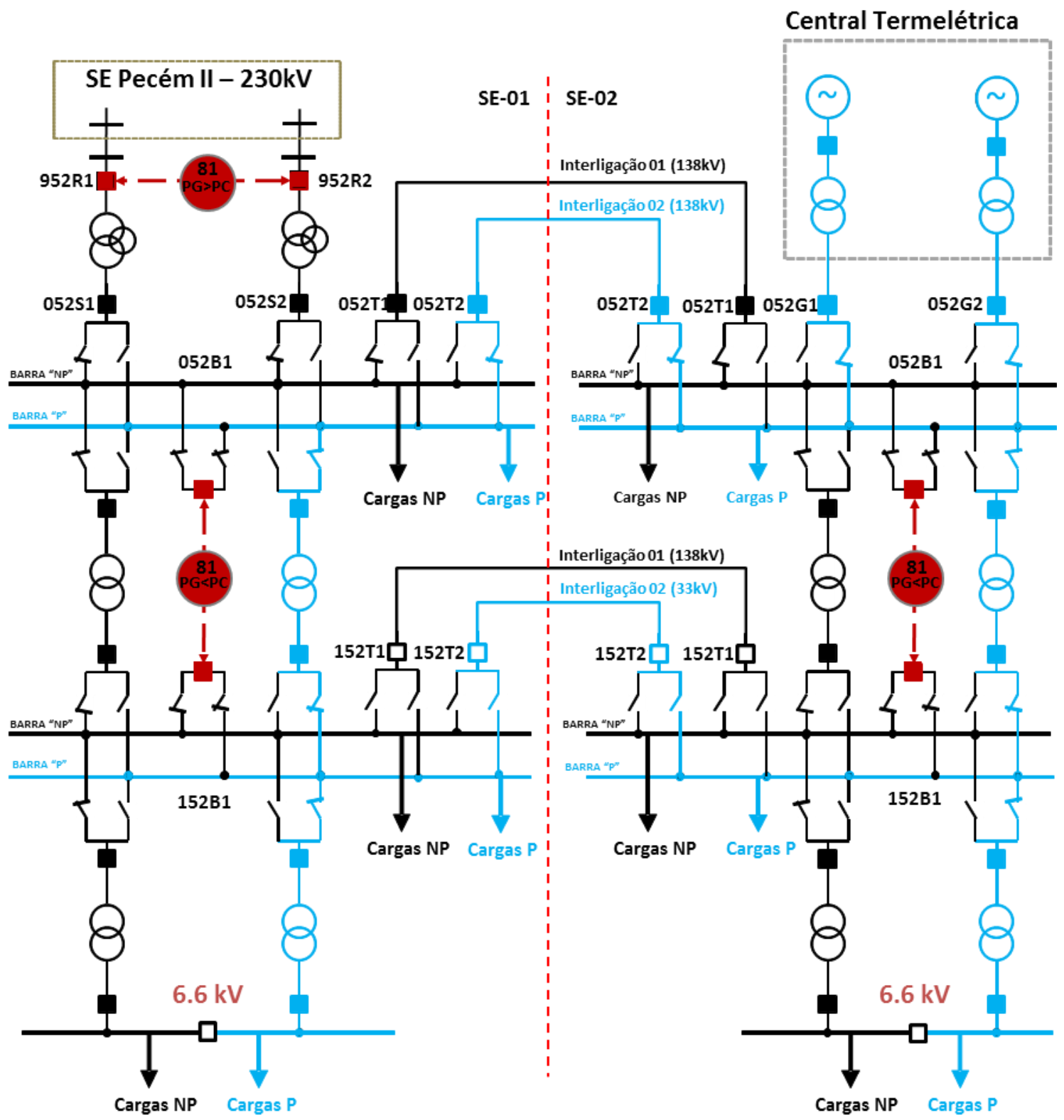

Figura 7. Representação de atuação do sistema de barra segura.

Para atuação do sistema de barra segura no caso de $P G<P C$, ou seja, potência gerada menor que potência de consumo, os barramentos de $138 \mathrm{kV}$ e $33 \mathrm{kV}$ serão separados através da abertura dos disjuntores de interligação, conforme figura 7. Com isso, as cargas conectadas terão seu fornecimento de energia oriunda de fontes diferentes, conforme o ponto de conexão definido. Dessa forma foi realizado estudo afim de se definir o grau de importância das cargas em meio ao processo siderúrgico, o resultado disso é o procedimento correto de disposição das cargas nos barramentos prioritários e não prioritários, para que em caso de atuação, as cargas conectadas aos barramentos prioritários possuam seu fornecimento de energia estabilizado e contínuo através das termoelétricas internas, assim diminuindo ou eliminando os efeitos provocados pelos distúrbios. 
É de grande importância que no momento de atuação do caso $P G<P C$, o montante de carga conectado aos barramentos prioritários seja inferior a potência total gerada pelas termelétricas, isso por motivos operacionais do processo de geração, dessa forma evitando afundamentos de frequência internos ou até mesmo desarme dos geradores por proteções intrínsecas do mesmo.

Para um melhor controle da disposição das cargas entre os barramentos, o sistema supervisório de operação das subestações foi alterado, proporcionando indicação visual em tempo real aos operadores sobre a potência disponível no barramento prioritário. Dessa forma e sabendo-se da instabilidade de consumo das cargas em questão, foi considerado um valor mínimo de excesso de geração denominado reserva girante, ou seja, o barramento prioritário deve possuir montante de carga inferior a geração mais a reserva definida.

$$
\begin{gathered}
P G>[P C(\text { barra prioritária })+\text { Reserva girante }(\%)](1) \\
\text { Reserva girante }=P G *(\% \text { definido })(2)
\end{gathered}
$$

$\mathrm{Na}$ equação 1, o valor de PC é dado pelo somatório de todas as cargas conectadas nos barramentos prioritários, já o valor de PG é dado através do somatório das potências geradas das unidades geradoras. Na equação 2, o valor percentual é definido em $10 \%$, logo em caso de atuação no caso de $P G<P C$, os barramentos prioritários possuirão no mínimo um excesso de geração de $10 \%$ do montante gerado, de modo a proporcionar mais segurança à estabilidade do processo de geração.

Em caso de isolamento total da usina, por atuação do caso de $P G>P C$, toda a planta terá seu fornecimento de energia oriundo das unidades geradoras internas, desta forma todo excedente de potência gerada será rejeitado pela mesma de forma rápida e automática, evitando elevação de frequência no sistema de distribuição.

\section{MATERIAIS E MÉTODOS}

Para aplicação do sistema em questão, foram realizadas modificações nos circuitos de controle das subestações, bem como alteração e criação das lógicas de atuação dos relés de proteção já instalados, não sendo necessário dessa forma qualquer investimento com novos equipamentos ou mão de obra, já que toda instalação, teste final de aceitação e modificação dos projetos, foram realizadas pelo corpo técnico da própria CSP.

Os valores dos parâmetros utilizados na função 32, direcional de potência ativa, foram definidos pelo corpo técnico CSP após análise do histórico de exportação da planta, já os valores dos parâmetros da função $81 \mathrm{U} / O$ foram empregados conforme resultados encontrados em estudo realizado pela empresa contratada FIGENER, a qual realizou simulações de perturbações no sistema de distribuição, afim de evidenciar comportamento eletromecânico da planta. Para tanto, foi utilizada ferramenta computacional como o programa CEPEL ANATEM. Na tabela 1 estão listadas algumas das perturbações simuladas e na figura 8, uma visão geral do ponto de conexão da planta. 
Tabela 1. Relação de eventos simulados

\begin{tabular}{cl}
\hline Evento & \multicolumn{1}{c}{ Descrição simplificada } \\
\hline 01 & Perda de uma da LTs SE Pecém II - CSP \\
\hline 02 & Perda do circuito LT SE Pecém II (500kV) - Fortaleza 2 (500kV) \\
\hline 03 & Perda do circuito duplo LT Teresina 2 (500kV) - P. Dutra (500kV) \\
\hline 04 & Perda SE Pecém II (500kV) \\
\hline 05 & Perda interligação N-NE \\
\hline 06 & Perda da UTEs Porto Pecém 1 e 2 \\
\hline 07 & Apagão no subsistema NE (ocorrido de 28/03/2013)
\end{tabular}

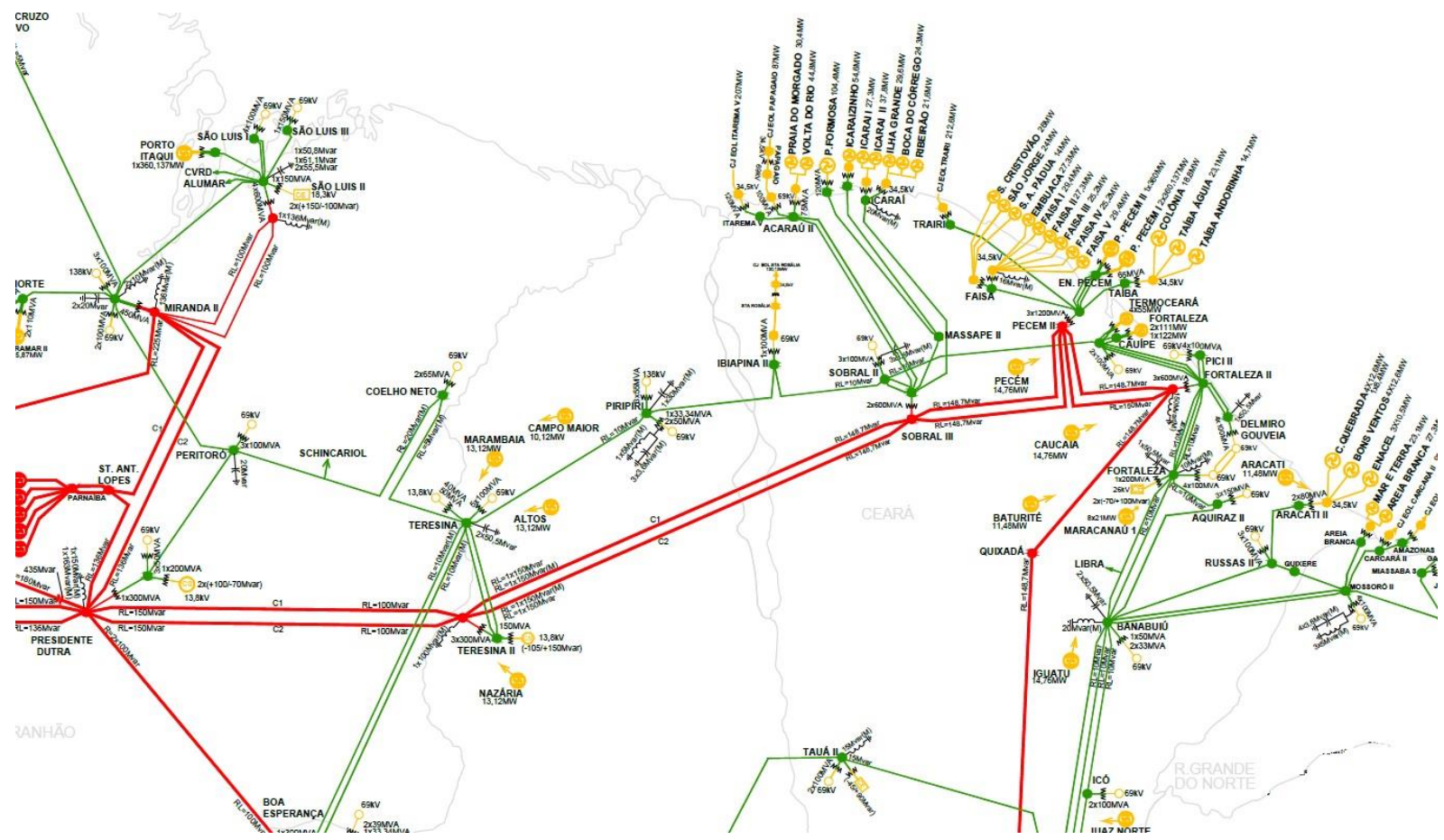

Figura 8. Região nordeste do SIN.

Dentre todos os resultados encontrados nas simulações, destacaram-se os efeitos eletromecânicos indesejáveis em motores síncronos, tais como motorização das unidades geradoras e torque excessivo no eixo dos moto-sopradores, como também instabilidade no acionamento de máquinas por desenergização de bobina dos contatores de comando, fenômeno conhecido como drop-out de contatores. Com os resultados encontrados foram definidos os valores de ajuste de frequência, os quais ocasionam atuação do sistema de barra segura antes dos efeitos provocados pelos distúrbios.

\section{RESULTADOS E DISCUSSÃO}

Após implantação de todo o sistema, foram realizados testes de atuação utilizando ferramenta de alta precisão, como maleta de teste OMICRON modelo CMC 356, simulando situações reais de distúrbios de frequência para ambos os casos de atuação, como $P G>P C$ e $P G<P C$. Junto às injeções de grandezas de caráter analógico nos relés de proteção, foram realizadas aquisições dos sinais de respostas dos equipamentos envolvidos, tais como disjuntores e relés de proteção. 
Com isso, evidenciou-se que o sistema de barra segura é hábil e estável, já que em todos os testes realizados o sistema funcionou conforme esperado e com o tempo de atuação de 116 milissegundos, onde o estimado em estudo foi de 150 milissegundos. No gráfico da figura 9, gerado via simulação para o caso de queda de frequência no SIN em uma situação de $P G>P C$, é possível visualizar que após a atuação do sistema de barra segura, a frequência das barras de 138kV da SE-01 se estabiliza conforme automatismo das termoelétricas internas, já as barras de 230kV na SE-Pecém II, por permanecerem conectadas ao SIN sofrem com afundamento de frequência com uma taxa aproximadamente de 1,5 hertz por segundo, situação que comprometeria totalmente o processo siderúrgico da planta, podendo causar danos irreversíveis a equipamentos como motores síncronos, por exemplo.

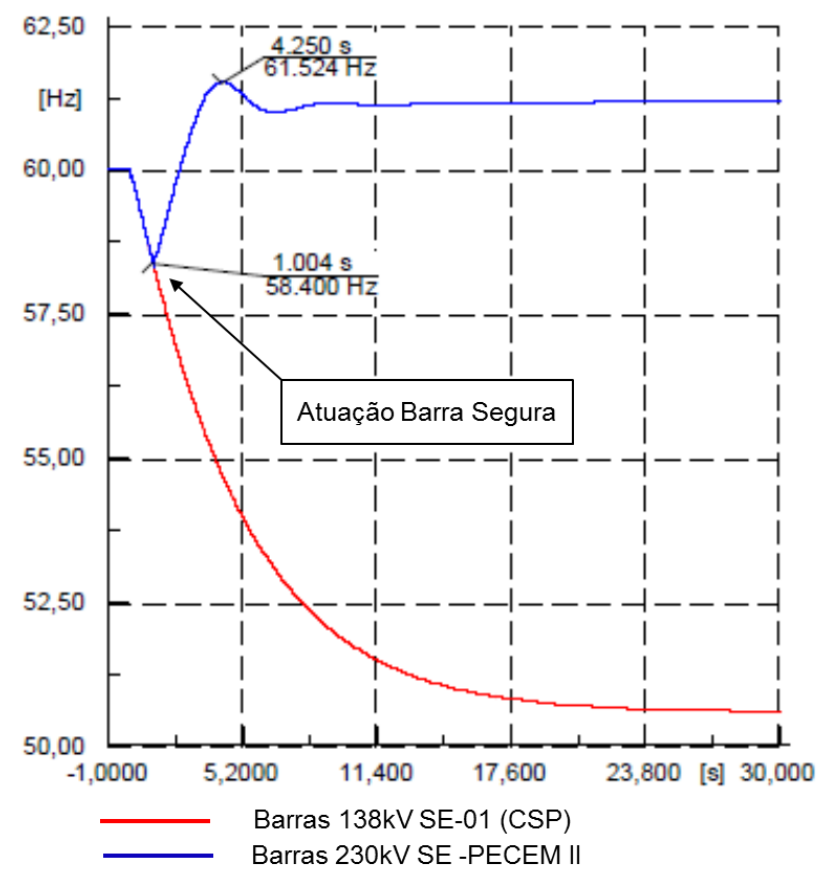

Figura 9. Gráfico de simulação para queda de frequência no SIN.

Após análise do relatório emitido com teste e valores encontrados em simulações, a CSP entende como forma de melhoria a substituição do modelo do relé de proteção $81 \mathrm{U} / \mathrm{O}$ atualmente utilizado, devido ao fato do mesmo ser responsável por aproximadamente 80 milissegundos dos 116 milissegundos encontrados em teste.

\section{CONCLUSÃo}

Com base nos estudos realizados pela empresa FIGENER, resultados encontrados em simulações reais e avaliação do comportamento do sistema pelo corpo técnico CSP, concluiu-se que para um tempo de atuação de 116 milissegundos, onde o esperado era de 150 milissegundos, o sistema de barra segura para ambos os casos de atuação é eficaz, proporcionando maior confiabilidade para o sistema elétrico da usina em uma situação de oscilação grave de frequência, com uma melhor estabilidade total da planta ou para piores casos como o de $\mathrm{PG}<\mathrm{PC}$, possibilitando a parada total sem ocasionar perdas de materiais ou danos em equipamentos. 


\section{REFERÊNCIAS}

1 ONS, Operador Nacional do Sistema Elétrico. DU-CT.NNE.01_r139 [imagem na internet]. [acesso em 29 maio 2017]. Disponível em:

http://www.ons.org.br/conheca sistema/mapas sin.aspx

2 João Mamede Filho, Daniel Ribeiro Mamede. Proteção de Sistemas Elétricos de Potência. Rio de Janeiro: LTC; 2016.

3 ONS Operador Nacional do Sistema Elétrico [página da Internet]. 2017 [acesso em 29 maio 2017]. Disponível em: http://www.ons.org.br/home/

4 Eliel Celestino da Silva. Proteção de Sistemas Elétricos de Potência, guia prático de ajustes. Rio de Janeiro: QUALITYMARK; 2014.

5 Hélio Creder. Instalações Elétricas. Rio de Janeiro: LTC; 2016.

6 Clever Pereira. Redes Elétricas Instalações Elétricas, no domínio da frequência técnicas de análise, modelos de componentes. São Paulo: ARTLIBER; 2015. 